International Journal of Instruction e-ISSN: 1308-1470 • www.e-iji.net

Article submission code: 20191127213430

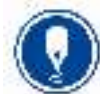

January $2021 \bullet$ Vol.14, No.1

p-ISSN: 1694-609X

pp. $567-586$

Received: 27/11/2019

Revision: 12/07/2020
Accepted: 03/08/2020

OnlineFirst:31/10/2020

\title{
Developing Action Research Model for Thai Tertiary Classrooms
}

\section{Afifi Lateh}

Faculty of Education, Prince of Songkla University, Thailand, afifi.l@psu.ac.th

Mahdee Waedramae

Faculty of Education, Prince of Songkla University, Thailand, mahdee.w@psu.ac.th

Weahason Weahama

Faculty of Education, Prince of Songkla University, Thailand, weahason.w@gmail.com

Supansa Suvanchatree

Faculty of Education, Prince of Songkla University, Thailand, supansa.s@psu.ac.th

Noorasikin Yeesaman

Faculty of Education, Prince of Songkla University, Thailand, nuraasikin.h@psu.ac.th

\section{Supakan Buathip}

Faculty of Education, Prince of Songkla University, Thailand, upakan.s@psu.ac.th

\section{Sinee Khuhamuc}

Faculty of Education, Prince of Songkla University, Thailand, sinee.k2527@gmail.com

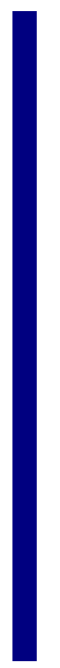

This participatory action research aims to (1) construct a classroom research development model for Thai tertiary lecturers in the three southern border provinces and (2) evaluate their classroom research performance. Through voluntary participation, the target group comprises 40 lecturers in Thailand, specifically from Prince of Songkla University, Pattani Campus; Yala Rajabhat University; Princess of Naradhiwas University; Fatoni University; and Boromarajonani College of Nursing Yala. In-depth interviews were conducted with two university administrators, and a focus group discussion was held for 12 participants, including lecturer representatives and the researchers. Initial data on suggestions were collected to construct a draft classroom research development model which was subsequently assessed for quality by three purposively sampled experts. The selection criteria for these experts included having a research background in Education or having conducted at least three research titles on classroom research. The instruments were an in-depth interview form, a focus group discussion form, a model quality assessment, a self-assessment form, and a learning log. The data were analysed with content analysis and descriptive statistics.

Keywords: classroom research, coaching, mentoring, Thai tertiary, lecturers

Citation: Lateh, A., Waedramae, M., Weahama, W., Suvanchatree, S., Yeesaman, N., Buathip, S. \& Khuhamuc, S. (2021). Developing Action Research Model for Thai Tertiary Classrooms. International Journal of Instruction, 14(1), 567-586. https://doi.org/10.29333/iji.2021.14134a 


\section{INTRODUCTION}

According to the Notification of the Ministry of Education Thailand on Higher Education Standards B.E. 2561 (2018), three standards for student outcomes were issued. Two of the mandates are directly relevant to the ways tertiary lecturers manage their learning. Section 1.1, which requires tertiary lecturers to be knowledgeable, capable, and well-rounded in bodies of knowledge about seeking legal carriers, maintaining stability, and sustaining life quality of individuals, families, communicates, and societies. Such lecturers should also be moral, perseverant, hardworking, and professionally ethical. Section 1.2 requires them to be innovative, equipped with $21^{\text {st }}$ century skills, and capable of integrating multidisciplinary knowledge for social development or in solving social problems. Furthermore, such lecturers should also possess entrepreneurship skills and keep up with social and global dynamics. To meet these standards in teaching, lecturers can no longer organize passive learning by giving lectures, explanations, and demonstrations. It is imperative to redesign the teaching through lesson plans with learning activities that promote learners' opportunities to conduct research and take action. With this pedagogical approach, lecturers should slightly step back, suggest, assist, and guide only to wait for the learners to autonomously establish their bodies of knowledge. This type of proactive learning activities is known as active learning.

When implementing active learning, lecturers should resort to keep learners challenged and afford to stimulate their hunger to grasp the concepts. The purpose of such efforts is to facilitate learners towards establishing bodies of knowledge which produce sustainable learning outcomes as well as accurate and wise future applications. Hence, lecturers in charge of similar or different courses may need to collaborate and share success stories about their implemented active learning activities so that others can identify classroom challenges and find strategies to produce optimal learning outcomes.

To identify the tangible success of active learning in solving classroom problems, classroom research is necessary. Freeman (1998) proposed a six-stage cycle for classroom research, including 1) create doubts about classroom operations; 2) establish questions; 3) collect data; 4) analyse data; 5) interpret the acquired information; and 6) publicize the findings. From the above steps, the lecturers should start by surveying and analysing problems. If multiple problems have emerged from the survey and analysis, prioritize them based on severity. The more severe, the earlier it needs solving. However, in solving such an issue, practicality also plays a role. Hence, determine whether it is practically solvable. Subsequently, come up with a course of action to solve or develop a solution to counteract the problem. In this stage, lecturers should find supportive data to confirm the possibility of the ideas. These data could either be from theoretical statements, research articles, or other relevant documents regarding past experiments. Partially, the data will be a crucial confirmation indicating how likely the lecturer-selected approach can tackle the problems or be extended into strategies and innovations. Through this stage, theories or related literature are incorporated to invent new teaching methods, behavioural modifications, and teaching innovations that the lecturers have never implemented before but believe promising against their specific 
classroom problems. Subsequently, the developed pedagogies or innovations are applied. The application procedures should be clear on who the targets are, when to take which actions, and how each activity is carried out. Simultaneously, the results of such implementation should be recorded, possibly through notes, interviews, tests, and questionnaires. Finally, conclude and reflect the results through proper statistical analyses. Indicate clearly whether such pedagogies or innovations succeed, solve target problems, as well as meet goals and expectations. Towards the end, the lecturers should outline the strengths and weaknesses of the experimentation and suggest ideas for further applications.

Classroom research involving active learning experiments has consistently been conducted from past to present covering pre-school, elementary, and secondary levels. This type of research can be conducted in any semester or throughout an academic year since different choices of learning contexts, learners, teachers, social groups, and environments could reveal different contextual solutions. Teaching professionals who conduct classroom research are called "teacher-researchers" as described in Carr and Kemmis (1986); Patterson, Santa, Short, and Smith (1993); Santa and Santa (1995); MacLean and Mohr (1999); Gray and Campbell-Evans (2002); and Vásquez (2017). Nonetheless, with multiple tasks being assigned to tertiary lecturers (for instance, teaching, research, academic services, and cultural preservation), classroom research being part of the professional responsibility to ensure learners meet the designated learning goals and outcome standards is considered an additional burden being thrown into the already dense responsibility pile. Only those at faculties of education could utilize the classroom research findings in their responsible field-specific research. Others are expected to do both: classroom and field- or curriculum-specific. Consequently, many tertiary lecturers do not attempt to conduct classroom research. When compared with the total number, only a few of them do. This phenomenon is reflected through the actions that tertiary administrators and university offices are urging their lecturers to simultaneously conduct classroom research in their responsible courses.

Universities in the three southern border provinces of Thailand (Narathiwat, Pattani, and Yala) are affected by the political unrest. Many parents in non-local regions do not permit their children to admit to universities in the area. As a result, the learning environments lack diversity making it more difficult than usual for learners to engage in different learning activities, introduce various ways of life, and learn non-local cultures. Hence, it is vital for tertiary lecturers to incorporate multiple active learning techniques to achieve the mandated Higher Education Standards. Practically, some of the techniques include helping learners with substandard basic knowledge such as those in the lowest tiers of Thailand ordinary national educational test ranking. With the help of classroom research, discoveries and problem-solving are expected to be more accurate. Therefore, this study has the following research objectives:

1. To construct a classroom research development model for Thai tertiary lecturers in the three southern border provinces; and 
2. To evaluate the Thai tertiary lecturers in the three southern border provinces on their classroom research performance.

\section{LITERATURE REVIEW}

Many scholars have defined the term "classroom research." For instance, Jamornmann (1994) stated that it is research conduct by teachers and for teachers. Teachers should address instructional problems, look up information, and use reliable processes to solve the problems. The research findings will become the answers which the teachers would apply to the classrooms in question to solve the problems. Furthermore, Newman (2000) explained that classroom research is action research that aims to interpret and describe everyday professional lives through operational processes that can simultaneously bring solutions to problems. Wongwanich (2006) defined the term as teacher-led, in-class research conducted to solve classroom issues where the results can be used to improve the teaching and learning or enhance the learning where learners would gain the ultimate benefits. This type of research has a fast pace. Its findings are instantly applied for immediate effects. Daily action data are shared, reflected, criticized, and discussed among school colleagues so that the implementations and effects are exchanged for optimal effectiveness and enhanced learning among teachers and students.

Studies that examine, present, and monitor classroom research conducts, propose classroom research development models, or evaluate tertiary classroom research performance in Thailand are scarce. For instance, Laotong, Promjit, Aonchan, and Chantarasompoch (2014) organized training and monitored the classroom research progress of lecturers at the Faculty of Management Technology, Rajamangala University of Technology Isan, Surin Campus. It appeared that, during the study, only 3 out of 15 courses $(20 \%)$ were able to successfully conduct classroom research. According to Samrit, Prachayapruit, and Bovornsiri (2015), a mentoring system was developed at Colleges of Nursing under Praboromarajchanok Institute, The Ministry of Public Health, the ten lecturers in care, were found to have produced extremely highquality classroom research. As for Junpeng and Tungkasamit (2014), which implemented a mentoring system to improve evaluation skills for lecturers at Khon Kaen University, it was reported that the target lecturers were able to plan and design the measurement and assessment tools, especially the authentic ones. The result before and after implementing the mentoring system was highly significant, and the targets were able to design learners' outcomes following the requirements set forth by the Thailand Higher Education Standards.

Most of the studies sought to propose research development models in response to primary research potential enhancement missions. For example, Wadeecharoenrat, Methakunavudhi, and Ritcharoon (2012) developed an empowerment model to enhance research potential and monitored the implementational performance. The results suggest that lecturers were empowered and produced high-quality research projects. SathiraAnant, Charoenwai, Wangpanich, and Chuanchom (2016) introduced a development of strategies for enriching the mentor instructors' competencies in the North-eastern part of Thailand, which mainly comprised strategies that foster positive relationships among academic mentors and new nursing/less-experienced lecturers. Sittisom, Chi-natrakul, 
Wimolkasem, and Sintanakul (2017) invented a faculty's research potential development model through a participative research process based on focus group discussions involving administrators, researcher lecturers, and representative lecturers from 40 Rajabhat universities nationwide. The model comprises input factors such as researcher mentoring systems, database systems, incentive systems, professional networks, training, and assessment systems along with a trilateral implementation that joins researchers, professional networks, and administrators together to achieve the policy-driven results and outputs.

Primarily, studies on classroom research development models tend to target elementary and secondary teachers. As seen in Suksomboon, Prayoon, and Jomhongbhitbhat (2015), a researcher teacher networks model on classroom action research for Secondary teachers, which blends online and offline learning, known as TNet CAR was developed. The implementation targeted 20 professionals in Phra Nakhon Si Ayutthaya Province who were interested in the scheme and applied as network members. The results demonstrated that the target group was able to compose 20 high-quality classroom action research titles. Rungreangwanitkun (2013) developed a competency enhancing model for teacher-researchers through a learning process integration model known as Smart Training. The study reported that 30 teacher-researcher participants earned higher mean scores in every performance aspect with statistical significance after using the model. Also, Sopakayang, Tammarat, and Pailai (2013) employed an action research model to examine teachers' potential development performance in conducting classroom research. The model operated in two cycles, and each contains four steps: planning, implementation, observation, and reflection. With the six target participants at Ban Huaikok 1 School under the Office of Mukdahan Primary Educational Service Area, the findings indicated that five of them gained better understanding of classroom research procedures, acquired necessary skills and confidence, and were able to appropriately conduct their classroom research. Rattana (2011) attempted to improve 35 teachers' classroom research potential at Songpittayakom School, Phrae Province using Kalyanamitr action research using a four-step classroom research framework comprising problem and cause identification, problem-solving determination, problem-solving implementation, and research conclusion and reporting. Operated in four cycles, there were three developmental strategies involved: workshops, counselling supervision, and autonomous learning supports. The findings illustrated that the teachers became knowledgeable and understood the classroom research principles and processes. They were able to compose classroom research proposals and action plans, take a proper course of action following designed procedures to manage the teaching, work with learners to implement the designed learning processes, publicize the findings, promote better understanding, and invite more volunteer teachers to join the research network. Quantitatively, the learners gained improved academic achievements whereas the teachers acquired more academic works in their portfolios. Consequently, $87.50 \%$ of the co-researchers in this network, who filed a promotional consideration request, were approved and promoted as Senior Professional Level teachers, whereas $26.32 \%$ of them were promoted as Professional Level teachers. 


\section{METHOD}

This participatory action research aims at tackling problems through the participation of the target group both as research participants and partners who would beneficially employ the research findings to eventually improve the practices of learning management (Carr \& Kemmis, 1986; Chandler \& Torbet, 2003; McNiff \& Whitehead, 2006). Efficiently utilized participatory action research is projected to benefits the target group in at least three aspects, including 1) increased knowledge, 2) increased actions, and 3) increased knowledge dissimilation (MacDonald, 2012; Sutthinarakorn, 2014). Initially, the researchers reviewed documents and studies related to the enhancement of research potential and extracted feedback from Phase 1 of the study where the participants suggested that there should be a mentoring and coaching system and some knowledge exchanges. Three supplementary factors that promote professional learning community were also employed: a potential activation leadership system for classroom management and research, a co-learning process for learner-focused development, a joint Kalyanamitr learning implementation plan (Lateh, Waedramae, Weahama, Suvanchatree, Yeesaman, Buathip,\& Khuhamuc, 2018). Kalyanamitr is a Thai word that refers to fruitful, glorious, honest, and facilitating friendship (Office of the Royal Society, 2016). Subsequently, the following developmental phases were implemented:

1. Two in-depth interviews were conducted with two purposively sampled university administrators with research backgrounds in Education. Specifically, the two administrators were represented faculties of education in Prince of Songkla University, Pattani Campus and Yala Rajabhat University. The data on model suggestions were collected and employed to construct the draft classroom research development model for the tertiary lecturers.

2. The draft was presented to the focus group discussion with 12 participants including five lecturer representatives in a ratio of one from each university (including Prince of Songkla University, Pattani Campus; Yala Rajabhat University; Princess of Naradhiwas University; Fatoni University; and Boromarajonani College of Nursing Yala), and seven researchers. The lecturer representatives were purposively sampled based on their backgrounds with at least three research titles conducted on classroom research. Later, additional suggestion data were compiled and used to enhance the model draft.

3. The updated model draft was then submitted to the three experts who are knowledgeable on classroom research and instructional model development. The draft went through a quality assessment for tertiary education on four aspects: suitability, feasibility, utility, and comprehensiveness. Finally, it was refined following the assessment results.

After the modifications according to the said developmental phases, the finalised classroom research development model for tertiary lecturers in the three southern border provinces was eventually implemented. The researchers asked the targets to run a selfevaluation and wrote reflections on their potential development.

\section{Participants}

The participants were 40 lecturers from Prince of Songkla University, Pattani Campus; Yala Rajabhat University; Princess of Naradhiwas University; Fatoni University; and 
Boromarajonani College of Nursing Yala. The participation was voluntary, and the figure included the five participants of the focus group discussion.

\section{Research Tools}

Three instruments were employed:

1. An in-depth interview form and a focus group discussion form for the participants to suggests changes to the classroom research development model for tertiary lecturers in the three southern border provinces, and the IOC range of .67-1.00.

2. A quality assessment form which evaluates four aspects of the developed model draft including suitability, feasibility, utility, and comprehensiveness with a 5-point rating scale indicating interpretations of extremely high, high, medium, low, and lowest and the IOC range of .67-1.00; and

3. A self-evaluation form and a learning log which seeks to a) record two learning aspects including learning-activity deliveries and classroom research conducts using a 10-point rating scale where 1 represents the fact that the comprehension and applicability direly requires improvement whereas 10 represents the fact that the comprehension and applicability is excellent, b) learning outcomes and benefits derived from the two activities, and c) other suggestions.

(see http://goo.gl/forms/vyElDYY7OLNikA9u2)

\section{Data Analysis}

Content analysis was employed to process the data from the in-depth interviews, the focus group discussion, and the participants' learning logs on the two dimensions, including learning-activity deliveries and classroom research conducts. Crucial insights were subsequently extracted and utilized to enhance the classroom research development model for Thai tertiary lecturers in the three southern border provinces. The self-evaluation of the participants on the two aspects were reported in mean and standard deviation with a result summary.

\section{FINDINGS}

The developmental results of the classroom research development model for tertiary lecturers in the three southern border provinces are reported in three of the following phases:

Phase 1 - Preparation and Planning: In this phase, operations were conducted in sequence using five steps: 1) preparing the community, 2) analysing limitations, 3) designing developmental strategies, 4) improving the leadership team, and 5) planning task executions. To prepare the community, the target group comprising tertiary lecturers in the three southern border provinces were informed about the study. Then, the barriers and limitations of classroom research were identified. Goals for future classroom research were targeted with proposed courses of developmental actions to achieve the set goals. Leadership team members received necessary briefings through informal dialogues on learning management techniques to organize learning activities, classroom research processes, team collaboration, and project management. Finally, the 
researchers and the leadership team members worked together to determine operational plans, procedures, and codes of conduct.

Phase 2 - Kalyanamitr Coaching and Mentoring: As previously discussed, "Kalyanamitr" refers to glorious and facilitating friendship. Kalyanamitr friends tend to unconditionally help friends with honesty. In this phase, six activities were carried out: 1) proposing teaching techniques and classroom research strategies; 2) collaborating in designs of learning activities and assessment; 3) composing a learning plan following the designed activities; 4) preparing assessment tools; 5) implementing the activities in class; and 6) writing relevant research articles. In this phase, the researchers also incorporated three supplementary factors to promote professional learning community: a potential activation leadership system for classroom management and research; a colearning process for learner-focused development; and a joint Kalyanamitr learning implementation plan. The purpose of these activities was to foster tertiary lecturers in the three southern border provinces to research in classrooms.

Initially, the researchers attempted to establish trust among the targets through motivation building by persuading the participants to feel the urge to change their learning activities. The researchers then worked as access facilitators to help the participants incorporate relevant theoretical contents into the learning activities, and the classroom research conducts, which is an effort in response to the authentic system. Various collaborating tasks were executed from designing learning activities based on designated pedagogies; utilizing activity-relevant media, materials, and tools; implementing assessment and measurement tools; to designing activity-based classroom research procedures. Furthermore, periodical sessions of team meetings and reflections were organized in every step of the activity management and classroom research. The researchers and the participants jointly analyse the operations and provide feedback to each step of the procedures. Self-study enhancement efforts were given to support the participants to ensure that unclarified doubts were minimized. In this phase, coaching and mentoring follows the principles of Kalyanamitr meaning that workflows are casually monitored and facilitated in a friendly environment, i.e., friend and brother/sister alike. Consultations are provided to support each step of the actions.

Phase 3 - Evaluation: The evaluation comprises two courses of action: 1) monitoring and 2) performance assessment. The primary purpose of this phase is to monitor, reflect, and improve the process so that data such as preliminary success factors and operational limitations could be extracted and reported to the community. In terms of barriers, proper procedural modifications were strategized to minimize difficulties, and the results were concluded.

The proposed classroom research development model for Thai tertiary lecturers in the three southern border provinces, under the code name of Kalyanamitr PLC Model, is exhibited as demonstrated in Figure 1. 


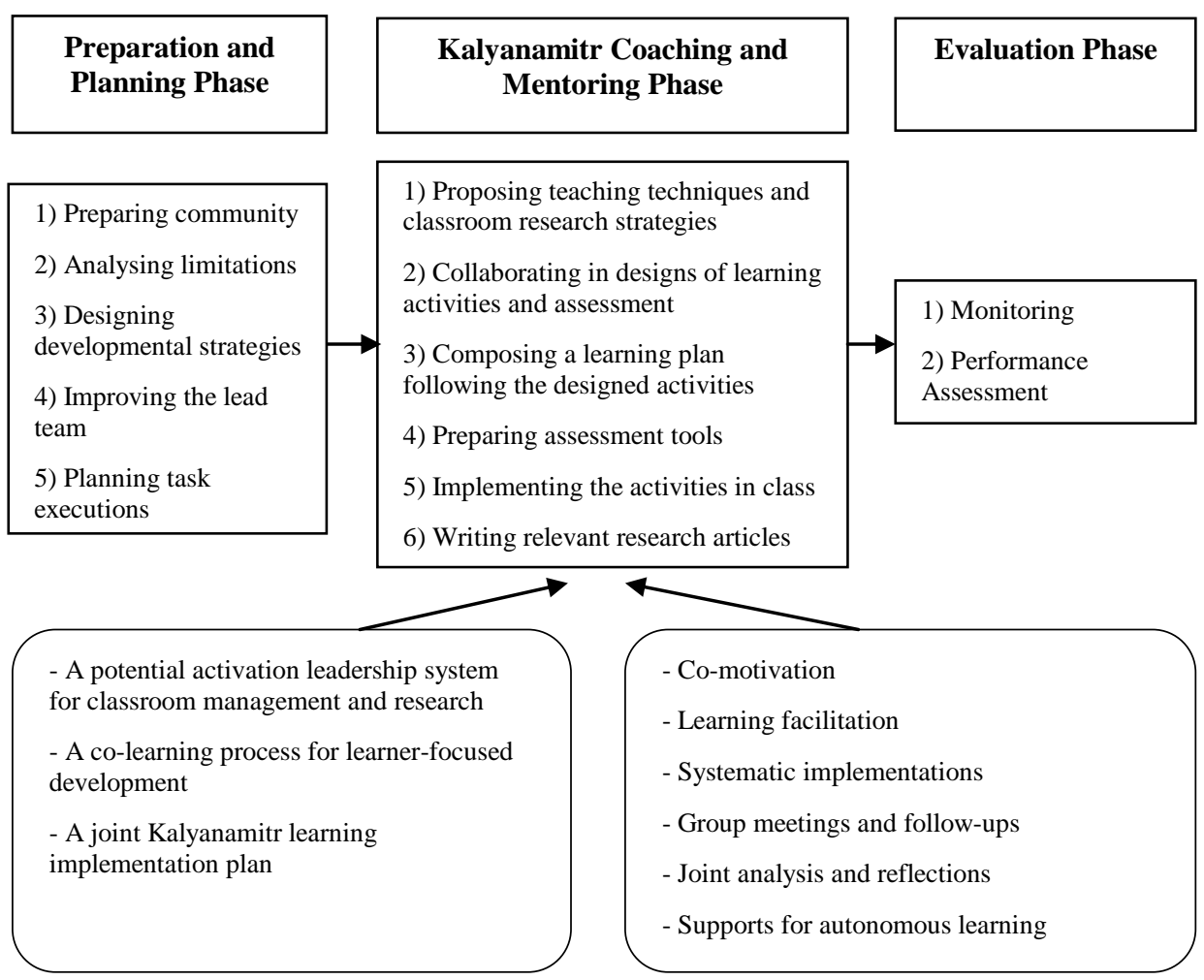

Figure 1

The developed classroom research development model for Thai tertiary lecturers in the three southern border provinces known as Kalyanamitr PLC Model

Before experimenting with the Kalyanamitr PLC Model, its first draft went through a quality assessment in four dimensions: suitability, feasibility, utility, and comprehensiveness. The result indicated that the model draft has exceptionally high quality with a mean of 4.82 and a standard deviation of 0.17 . Finally, the model draft was revised again according to the experts' suggestions to maximize its quality.

Consequently, the Kalyanamitr PLC Model yielded the following results:

1. The Preparation and Planning Phase, which was during October - December 2016, produced the results as follows:

1.1 Preparing community: The researchers ran a meeting to spread information about the research project, including goals, rationale, employed participatory principles, and lecturers' participation benefits. Accommodating 80 lecturer participants from Prince of Songkla University, Pattani Campus; Yala Rajabhat University; Princess of Naradhiwas University; Fatoni University; and Boromarajonani College of 
Nursing Yala, the meeting went over the concept reviews, principles of classroom research, experiences, and obstacles.

1.2 Analyzing limitations: Classroom research constraints and barriers were analyzed, and future goals of classroom research were determined. Each stakeholder group was given a floor to share the current situations and propose desirable future outcomes. Further, groups' representatives took a turn presenting their data and exchanging ideas. The participants in this stage were a faculty administrator; two lecturers each from Prince of Songkla University, Pattani Campus; Yala Rajabhat University; Princess of Naradhiwas University; Fatoni University; and Boromarajonani College of Nursing Yala; and seven researchers.

1.3 Designing developmental strategies: At this stage, goal-relevant developmental strategies and options were explored and cooperatively proposed. Justifications were also made to determine such developmental options, targets, and courses of action. The participants were the same parties as Section 1.2.

1.4 Improving the leadership team: The leadership team members were the seven researchers who were perceived to have adequate capabilities to promote better understanding of classroom research principles and processes. The leadership team members went through three informal briefing rounds touching on learning management techniques to organize learning activities, classroom research processes, team collaboration, and project management. Eventually, the leadership team was divided into three subgroups based on contents and responsibilities: learning-activity designs, preparation instructional ICT media (information communication technology), and classroom research conduct.

1.5 Planning task executions: The researchers organized a meeting with the two lecturer representatives from each university (i.e., Prince of Songkla University, Pattani Campus; Yala Rajabhat University; Princess of Naradhiwas University; Fatoni University; and Boromarajonani College of Nursing Yala) to mutually designate an action plan, work procedures, and collaborative codes of conduct. Multiple revisions were made until all parties were satisfied. Hence, the final revision was issued as the project's plan.

2. Kalyanamitr Coaching and Mentoring Phase: After the researchers distributed letters to 80 lecturers in the five institutions who participated in the project's information meeting, 60 responded with positive confirmations (whereas the designed sample size was 40). Subsequently, the researchers filed permission requests to the targets' respective supervisors, asking for approvals for the prospective participants to join an academic-year-long developmental research program. Operations in this phase involved Kalyanamitr-style coaching and mentoring which all the facilitations simulate the situations when friends were to help friends, or big brothers/sisters were to help little brothers/sisters. Such casually friendly facilitations included consultations through every step of the procedure starting from the preparation meeting which sought to inform the participants about plans and operations that would take place throughout the developmental duration. 
The researchers established a FaceBook group, "Kalyanamitr Action Research," as an additional communication channel besides telephone and email. Nevertheless, the number of potential participants from the five institutions during this preoperational phase was decreased to 56 . The results are briefly reported as follows:

2.1 Proposing teaching techniques and classroom research strategies: The research team worked together to examine the learning-activity strategies inspired by various pedagogical techniques, review classroom research options, and share the previously employed methods with one another. Afterward, a technical instructional summary was produced and introduced to the participants. The contents include problem-based, project-based, activity-based, and model-based learning; group activities; flipped classrooms; blended learning; cooperative learning; role-playing; peer-assisted learning; and mind mapping. In terms of learning outcomes, in addition to improving the academic achievement, the participants also aimed to develop different skills, such as sports, Chinese speaking, teamwork, problem-solving, knowledge-seeking, assertiveness, and learning participation. This activity was conducted between January and February 2017 holding four group meetings in total.

2.2 Collaborating in designs of learning activities and assessment: At this stage, to ensure that the learning produces desirable outcomes, the research team worked with the participants to brainstorm and design the learning activities perceived to be consistent with the selected pedagogies as well as means to assess such learning. In this activity, the participants had to either design 1-3 learning units or all units for the entire subject. In terms of assessment, multiple-choice tests, open-ended tests, observation assessment, evaluation forms, and questionnaires were employed. Also, some participants incorporated online apps (such as Kahoot, Quizizz, Socrative, and Plickers) in their learning activities. This activity was conducted during March-May 2017 involving six group meetings. After completing the activity at this stage, the number of participants from the five institutions decreased to 36 , which is four people lower than the set target.

While carrying out the first and second activities, the researchers attempted to help to motivate the participants and convince them to see the benefits to be gained from the learning transformations using diverse teaching techniques. The researchers also introduced steps to employ instructional techniques in designing learning activities and study the learning through classroom research so that the learning can be in control and yield desirable academic outcomes.

2.3 Composing a learning plan following the designed activities: After introducing ways to write lesson plans, the participants crafted their plans following the designed learning activities. Then, the plans were shared and revised until they are ready for the upcoming teaching sessions. This activity was conducted in June 2017, hosting two group meetings.

2.4 Preparing assessment tools: In this activity, the researchers helped the participants compile the essential information needed for classroom research based on the 
designed and designated learning activities. The efforts included preparing instructional materials and assessment instruments. This activity was in July 2017 with two group meetings.

The researchers took the role of access facilitators during the third and fourth activities to supply the participants with necessary theoretical contents to fulfill their activity, learning, assessment, and classroom research goals. This facilitation was strategically employed to ensure that the participants feel relaxed and relieved so that all the operations were smooth, successful, and responsive to the authentic system. Various collaborating tasks were executed from designing learning activities based on designated pedagogies; utilizing activity-relevant media, materials, and tools; implementing assessment and measurement tools; to designing activity-based classroom research procedures.

2.5 Implementing the activities in class: After completing the first-fourth activities, the participants began implementing the learning activities in their classrooms. The researchers stood by to help with issues, worked together to overcome problems, and successfully achieve the planned goals. This activity was conducted between August 2017 and April 2018, involving six group meetings and a monitoring session for each institution. At this stage, the number of participants reduced to 20 from four institutions, which is $50 \%$ lower than the targeted participant quantity.

2.6 Writing relevant research articles: In this final stage, the participants were expected to craft their research articles and present the classroom research reports. The research team began with proposing the relevant principles or conceptual frameworks for the participants to use in coming up with the research titles as well as composing research backgrounds, objectives, hypotheses, scopes, findings, result discussions, future suggestions, and references. After that, the participants were tasked to write the research articles, with the assistance from the research team if necessary details were perceived missing and when some sections lacked completeness. This activity was conducted during May-June 2018, constituting two group meetings.

The fifth and sixth activities are mostly about team meetings and reflections where the researchers and the participants could jointly analyze the operations and provide feedback to each step of the procedures. Self-study enhancement efforts were given to support the participants to ensure that unclarified doubts were minimized.

3. Evaluation Phase: This evaluation phase was conducted in September 2018, covering two operational stages: 1) monitoring and 2) performance assessment. In the monitoring stage, the researchers worked with the institutional representatives to reflect and update the model processes based on the previously planned deployment of the classroom research. The meetings were scheduled on every $15^{\text {th }}$ date of the months through formal (face-to-face) and non-formal (social media) interactions. This attempt was to monitor, reflect, and improve the model process so that data such as preliminary success factors and operational limitations could be extracted and reported to the community. In terms of barriers, proper procedural 
modifications were strategized to minimize difficulties, and the results were concluded. Based on the reflections, some activities were modified using various modification parameters such as time extension to explain more on pedagogical techniques and FaceBook-live broadcasts to demonstrate the use of the online apps. In terms of operational barriers causing the decreased number of participants, it was found that some were heavily burdened with excessive teaching hours, as high as 24-course credits per week. With such a burden, some participants could not consistently join the project. In addition to the teaching burdens, universities' projects, academic services, and administrative tasks also contributed to the difficulties. As a result, only 20 participants remained committed to pursuing their classroom research with the hope to publicize the findings and bring positive changes to the students. Furthermore, the 20 participants reflected that their knowledge of learning-activity designs and classroom research improved. Reportedly, they felt optimistic that their next research attempts would become even more successful.

For the performance assessment stage, the researchers were able to acquire 20 completed research articles from the four institutions (five from Prince of Songkla University, Pattani Campus; five from Yala Rajabhat University; eight from Princess of Naradhiwas University; and two from Boromarajonani College of Nursing Yala). Exemplified below are some of the submitted titles:

1. Flipped Classroom Performance towards Academic Achievement and Satisfaction in Instrumental Analysis of Undergraduate Students at Prince of Songkla University, Pattani Campus;

2. Project-based Learning in Social and Green Marketing in Enhancing Business Plans and Green Marketing Projects among Undergraduate Students in Yala Rajabhat University;

3. Learning Achievement from Blended Learning in Information Searching and Academic Writing of Undergraduate Students at Princess of Naradhiwas University; and

4. Model-based Learning Performance towards Simulating Child-delivery Experiences for Nursing Students Boromarajonani College of Nursing, Yala Province

In addition to the produced research articles, the participants were asked to conduct a self-evaluation and $\log$ their learning to indicate their classroom research performance after being exposed to the classroom research development model. Two assessment dimensions were used, and, as exhibited in Table 1, their mean performance scores of learning-activity management and classroom research were 8.11 and 7.00, respectively, out of 10 .

Table 1

Post-activity self-evaluation on the performance of learning-activity management and classroom research

\begin{tabular}{lll}
\hline Self-evaluation & Mean & Standard Deviation \\
\hline Learning-activity management & 8.11 & 1.27 \\
\hline Classroom research & 7.00 & 2.12 \\
\hline
\end{tabular}


In addition to the above self-evaluation, the participants also reflected through their learning logs, indicating that through this research project, their classroom research skills were strengthened. With the suggestions from mentors and coaches, their academic works improved. See the following log excerpts:

"...It is considered a good starting point as it helps me understand classroom research better..." (Amanee)

“...This significantly improved my classroom research skills..." (Hassan)

"The research team is friendly. It feels the big brothers and sisters are always there to help and suggest the little ones. All questions and doubts were clarified." (Wanpen)

"I wish there are more activities like, especially when they are about new teaching strategies." (Rawiwan)

"This activity offers enough opportunities for the participants to ask questions." (Pranee)

"I gained a better understanding of classroom research. However, I will still feel nervous if I were to do the research alone." (Anan)

\section{DISCUSSION}

The findings in this study are consistent with many past results. After Laotong et al (2014) organized training for lecturers at the Faculty of Management Technology, Rajamangala University of Technology Isan, Surin Campus, results indicated that only three from 15 courses (20\%) could produce classroom research articles. Samrit, et al (2015) developed a mentoring system with inputs, processes, products, and feedback through advisory, supervisory, and counselling mentorship and found that ten lecturers produced classroom research with outstanding quality. Suksomboon, et al (2015), which utilized a teacher-researcher networks model on classroom action research, was able to compose 20 high-quality classroom action research titles. Rungreangwanitkun (2013), which developed a competency enhancing model for teacher-researchers through a learning process integration model, reported that 30 participants earned higher mean scores in every performance aspect with statistical significance after using the model. Furthermore, Sopakayang, et al (2013), which employed an action research model to examine teachers' potential development performance in conducting classroom research, discovered that five targets gained a better understanding of classroom research procedures, acquired necessary skills and confidence, and were able to appropriately conduct their classroom research. Rattana (2011) employed Kalyanamitr action research to improve teachers' potential and discovered that 35 teachers reportedly understood the principles and processes of classroom research better. They were able to compose classroom research proposals and action plans, take a proper course of action following designed procedures to manage the teaching, work with learners to implement the designed learning processes, publicize the findings, promote better understanding, and invite more volunteer teachers to join the research network.

The reasons behind acquiring only $50 \%$ of the classroom research articles in this study were the hectic burdens imposed upon the lecturers. For instance, some of the lecturers 
were reported to have been taking charge of 24-course credits per week, and with such a burden, some participants could not consistently join the project until the end. In addition to the teaching burdens, universities' projects, academic services, and administrative tasks also contributed to the difficulties. Moreover, some project activities were forced to extend the durations due to incompatible schedules, mismatched free time, and other urgently prioritized university assignments. This phenomenon is congruent with the findings reported by Lateh et al (2018), indicating that Thai tertiary lecturers felt unconfident when it comes to the classroom-research knowledge as their current duties are excessively burdening and necessary administrative supports remain scarce. Similarly, Norasmah and Chia (2016) discovered that the excessive duty burdens, the lack of classroom-research knowledge, and the limited administrative supports provided are common problems among teachers in Malaysia. The same goes for Ulla, Barrera, and Acompanado (2017); Filipino teachers need more time and training allocated for classroom research. Nonetheless, the researchers believe that once classroom research is integrated into the typical teaching, the lecturers would not regard it as an extra or burdening task since it is an extension of what is partially done in class using the learners as targets and once problems are solved the learners and lecturers both gain benefits. In addition to the increased classroom research knowledge and skills, the lecturers would simultaneously be on a professional development track. As Newman (2000) mentioned, classroom research aims to interpret and describe typical professional lives through operational processes that can simultaneously bring solutions to problems. Also, Grima-Farrell (2017) reflected that what is valuable and easy for teachers to do is to take responsibility for their learners through the reflections of individual results, and one of the best ways to do so is through research.

The employed supplementary factors which promote professional learning community were consistent with the ideas proposed by Stoll, Bolam, McMahon, Wallace, and Thomas (2006), i.e., a professional learning community is an ad-hoc gathering where members share ideas and support one another in and out of classrooms to collectively seek pedagogical strategies to enhance the learning of their learners. According to William, Brien, Sprague, and Sullivan (2008) this type of community is constituted of three characteristics including professional development, use of data, and system-wide trust. Furthermore, the concept of a professional learning community is consistent throughout many studies. For instance, Kedwong (2013) discovered that five factors are required to establish a professional learning community: 1) a starting point for cooperation; 2) a platform for teachers to discuss and reflect ideas; 3) a group focus on learners' educational benefits; 4) a support to establish mutual values and norms; and 5) a support for work cooperation. Theparee and Patphol (2014) invented a development model for professional learning communities among Elementary teachers and found that a desirable model should consist of four elements: 1) learning culture, i.e., co-learning, cooperation, empowerment, value sharing, and organizational capability; 2) thinking method, i.e., synthetical, analytical, critical, creative, and problem-solving thinking; 3) best practice, i.e., total quality management, knowledge management, and benchmarking; and 4) continuous teacher professional development, i.e., knowledge 
accumulation, individual potential development, self-awareness of existing knowledge, self-awareness of missing knowledge, and knowledge incorporations for school reforms. Antinluoma, Ilomäki, Lahti-Nuuttila, and Toom (2018) discovered that Finnish professional learning communities comprise four core elements: 1) work culture; 2) leadership; 3) knowledge and skills of colleagues; and 4) participation in professional development, whereas a study in Malaysia, Abdullah and Ghani (2014), concluded that the community should contain five elements: 1) leaders that support and take part in learning; 2) shared visions, missions, and values; 3) mutual learning; 4) personal learning skills; and 5) facilitating conditions.

The findings of this study are similar to that of Lalor and Abawi (2014), which scoped its study to 11 Vietnamese teachers in international schools. The study examined how teaching experiences could positively reflect and establish professional learning communities. The report indicated that there are three elements involved: 1) sharing resources and pedagogical approaches; 2) social and emotional supports; and 3) focused professional learning. When classroom research findings were shared with a professional learning community, it was found that pedagogical development towards better learners' outcomes is crucial. Additionally, doing so helped promote leadership among the lecturers, convinced them to perceive the values of professional development, and simultaneously maximize their potential. Based on these notions, the researchers believe that if tertiary lecturers have some platforms to share knowledge about learning-activity development, designs, and implementation with extra simultaneous classroom research conduct, lecturers would feel motivated to improve their teaching regardless of institutional pushes. This motivation could passively occur from insightful reflective efforts contributed among professional colleagues, and such exchanges could automatically create a professional learning community. Furthermore, these exchanges, especially among the tertiary lecturer in the three southern border provinces, are projected to effectively yield satisfactory results among learners. However, it is also fair to mention that, with the Thai culture, some lecturers could be too polite and might avoid giving negative remarks or constructive suggestions. Hence, a committee or a responsible body should be established to encourage such constructiveness while maintaining the Kalyanamitr atmosphere. As evident in this study, the scheme was able to produce desirable results.

As previously discussed, friendly collaborating efforts from designing, planning, implementing, to reflecting among colleagues and mentors contributed significantly to the chance of classroom research success. The influencing factors of such success could be because the motivators were always there to stimulate, ask, or give opportunities for consultations. Consequently, the project managed to achieve its expected outcomes. This notion is in line with Intarakamhang et al (2018), which stated that the contributing factors for effective research and findings dissimilation among university lecturers are the university supports and the positive attitudes towards research, which are partially shaped by positive mentor traits. Congruently, Samrit, et al (2015) developed a mentoring system where the mentors took advisory, supervisory, and counselling roles, the ten lecturers in care were found to have produced extremely high-quality classroom research. Junpeng and Tungkasamit (2014) implemented a mentoring system to improve 
evaluation skills for lecturers at Khon Kaen University and reported that the target lecturers were able to plan and design the measurement and assessment tools, especially the authentic ones. The result before and after implementing the mentoring system was highly significant, and the targets were able to design learners' outcomes following the requirements set forth by the Thailand Higher Education Standards.

Although the term "Kalyanamitr" has previously been used in Rattana (2011) to improve the classroom research potential for teachers using Kalyanamitr action research through workshops, supervisions, counselling, and autonomous research, the study did not incorporate the coaching and mentoring processes, and the scope was limited to teachers in a secondary school. Another similar research with classroom research model was Rungruengwanitkun (2013), which constructed a potential development model for researcher teachers and integrated the model into a learning process for secondary school teachers. The model components included incentivisation, learning facilitation, systematic collaboration, group meeting, and follow-ups. Nonetheless, the Kalyanamitr PLC model of this study combined two other participatory elements driven in phases two with the friendly Kalyanamitr coaching and mentoring. Hence, the newly combined model offers more tangible and systematic operational procedures that are projected to be easier for teachers of any levels across the Thai regions and other edges of the world to follow.

\section{CONCLUSION}

The classroom research development model for tertiary lecturers in the three southern border provinces was developed in three phases: preparation and planning, Kalyanamitr coaching and mentoring, and evaluation. This model is significant for its utilization of the Kalyanamitr principles during the coaching and mentoring phase which involve six facilitating activities: 1) proposing teaching techniques and classroom research strategies; 2) collaborating in designs of learning activities and assessment; 3) composing a learning plan following the designed activities; 4) preparing assessment tools; 5) implementing the activities in class; and 6) writing relevant research articles. With this model, 20 classroom research titles were successfully produced by the tertiary lecturers from the four institutions.

In terms of limitations, since tertiary lecturers are not required to conduct classroom research nor that its outcomes are part of any academic-title criterion consideration, many lecturers perceived no dire needs to see it through. As previously discussed, tertiary lecturers are typically overwhelmed with core duties. However, some requirements from the Thailand Higher Education Commission and some standards from some universities may apply, and these require some lecturers to conduct classroom research and submit its findings to support the consideration of the Professional-Teacher promotion. This condition might play a vital role in the future in motivating relevant lecturers. Future studies should redo a resembling examination again by finding strategies to improve success ratio for classroom research conducts. Also, a knowledge transfer platform should be established to provide consistent classroom-research learning and skill enhancement as well as give a stimulating boost for lecturers to constantly produce research pieces. Furthermore, a classroom-research committee 
should be dedicated to ensuring that implementational and monitoring efforts are adequately provided. At the same time, long-term actions should be taken to foster the efficiency and creativity of learning-activity management and learner assessment because these processes take time. If tertiary lecturers are well knowledgeable about the issues, classroom-research potential development should be less time-consuming.

\section{REFERENCES}

Abdullah, Z., \& Ghani, M.F.A. (2014). Professional learning community in secondary schools community in Malaysia. Journal of Education and Learning, 8(3), 227-248. https://doi.org/10.11591/edulearn.v8i3.265

Antinluoma, M., Ilomäki, L., Lahti-Nuuttila, P., \& Toom, A. (2018). Schools as professional learning communities. Journal of Education and Learning, 7(5), 76-90 https://doi.org/10.5539/jel.v7n5p76

Carr, W. \& Kemmis, S. (1986). Becoming Critical: Education, Knowledge, and Action Research. London: The Falmer Press.

Chandler, D., \& Torbert, B. (2003). Transforming inquiry and action interweaving 27 flavors of action research. Action Research, 1, 133-152.

Freeman, D. (1998). Doing teacher-research: From inquiry to understanding. Pacific Grove: Heinle \& Heinle Publishers.

Gray, J., \& Campbell-Evans, G. (2002). Beginning teachers as teacher-researchers. Australian Journal of Teacher Education, 27(1), 1-22. http://dx.doi.org/10.14221/ajte.2002v27n1.4

Grima-Farrell, C. (2017). What matters in a research to practice cycle? Teachers as researchers. Springer Singapore: Springer Science+Business Media Singapore. https://doi.org/10.1007/978-981-10-2087-2

Higher Education Standards B.E. 2561 (2018, August 17). Royal Thai Government Gazette. Vol. 135 Special Edition 199 Ngor pp. 19-21.

Intarakamhang, U., Ekpanyaskul, C., Kijtorntham, W., Wattananonsakul, S., Wanichakorn, A., Pimthong, S., Prasertsin, U., Tuntivivat, S., Chavanovanich, J., \& Sutipan, P. (2018). Causal factors influencing research proposal development and research publication of faculty members in Srinakharinwirot University by the mediating impact of qualification of the mentors. Journal of Behavioral Science for Development, 10(1), 42-62.

Jamornmann, U. (1994). Action Research. Bangkok: Chulalongkorn University Press.

Junpeng, P., \& Tungkasamit, A. (2014). The continuing professional development of the assessment through research-based learning in higher education of Thailand. Procedia Social and Behavioral Sciences, 143, 737-742.

Kedwong, P. (2013). Proposition of Guidelines for Building Professional Learning Communities in Schools under the Office of Pathumthani Primary Educational Service Area 2. Master's Thesis in Education, Phranakhon Sri Ayutthaya Rajabhat University. 
Lalor, B., \& Abawi, L. (2014). Professional learning communities enhancing teacher experiences in international schools. International Journal of Pedagogies and Learning, 9(1), 76-86. https://doi.org/10.1080/18334105.2014.11082021

Laotong, P., Promjit, A., Aonchan, P., \& Chantarasompoch, K. (2014). Classroom research development of lecturers at Faculty of Management Technology, Rajamangala University of Technology Isan, Surin Campus. The Journal of Graduate School, Pitchayatat, 9(1), 75-84.

Lateh, A., Waedramae, M., Weahama, W., Suvanchatree, S., Yeesaman, N., Buathip, S., \& Khuhamuc, S. (2018). Factor analysis of classroom research competency enhancement among university lecturers. Veridian E-Journal Silpakorn University, Thai Edition in Humanities, Social Sciences, and Arts, 11(1), 2099-2115.

MacDonald, C. (2012). Understanding participatory action research: A qualitative research methodology option. Canadian Journal of Action Research, 13(2), 34-50. https://doi.org/10.33524/cjar.v13i2.37

MacLean \& Mohr. (1999). Teacher-Researchers at Work. National Writing Project: Berkeley, CA.

McNiff, J. \& Whitehead, J. (2006). All you need to know about action research. Thousand Oaks, CA: Sage.

Newman, J.M. (2000). Action research: A brief overview. Forum: Qualitative social research. $1(1), \quad$ Art $17 . \quad$ http://www.qualitativeresearch.net/index.php/fqs/article/view/1127/2507

Norasmah, O., \& Chia, S. Y. (2016). The challenges of action research implementation in Malaysian schools. Pertanika Journal of Social Science and Humanities, 24(1), 4352 .

Office of the Royal Society. (2016). Royal Institute Dictionary B. E. 2554. Retrieved 25 April, 2016 from http://www.royin.go.th/dictionary/

Patterson, L., Santa, C., Short, K., \& Smith, K. (1993). Teachers are researchers: Reflection and action. Newark, DE: International Reading Association.

Rattana, L. (2011). Classroom research potential development for teachers through Kalyanamitr action research: A case of Songpittayakom School, Song District, Phrae $\begin{array}{lllll}\text { Province. } & \text { Retrieved } & 2 & \text { June, } & 2014\end{array}$ http://www.songpit.ac.th/innovare/research_leadchai.pdf

Rungreangwanitkun, O. (2013). The model development to enhance researchers' competency for teachers in Secondary Educational Service Area Office 2 by learning process integration. Doctoral Dissertation in Education in Adult Education Program, Srinakharinwirot University.

Samrit, W., Prachayapruit, A., \& Bovornsiri, V. (2015). Development of a mentoring system for developing faculty members, Ability to do classroom action research at Colleges of Nursing Under Praboromarajchanok Institute, the Ministry of Public Health. Journal of Nursing and Education, 8(2), 67-82. 
Santa, C.M., \& Santa, J.L. (1995). Teacher as researcher. Journal of Reading Behavior, 27/3, 439-451. https://doi.org/10.1080/10862969509547891

Sathira-Anant, S., Charoenwai, S., Wangpanich, P., \& Chuanchom, S. (2016). A development of strategies for enriching the mentor instructors' competencies in the North-eastern part of Thailand. Journal of Educational Administration Khon Kaen University, 12(1), 31-41.

Sittisom, W., Chi-natrakul, R., Wimolkasem, N., \& Sintanakul, K. (2017). Faculty's research potential development by utilizing participative research process. Ph.D. in Social Sciences Journal, 7(3), 133-147.

Sopakayang, R., Tammarat, P., \& Pailai, T. (2013). Development of the teachers' potential in conducting classroom researches at Ban Huai Kok 1 School under the Office of Mukdahan Primary Educational Service Area. Journal of Graduate Studies, 10(49), 27-33.

Stoll, L., Bolam, R., McMahon, A., Wallace, M., \& Thomas, S. (2006). Professional learning communities: a review of the literature. Journal of Educational Change, 7(4), 221-258. https://doi.org/10.1007/s10833-006-0001-8

Suksomboon, S., Prayoon, B., \& Jomhongbhitbhat, B. (2015). Development of teacher networks model on classroom action research by self-efficacy for teachers under the Secondary Educational Service Area Office 3. SWU Educational Administration Journal, 12(23), 23-36.

Sutthinarakorn, W. (2014). Participatory Action Research and Conscientization. Bangkok: Kledthai.

Theparee, P. \& Patphol, M. (2014). A development of professional learning community model for the primary school teachers. Silpakorn Educational Research Journal, 6(2), 284-296.

Ulla, M. B., Barrera, K. I. B., \& Acompanado, M. M., (2017). Philippine classroom teachers as researchers: Teachers' perceptions, motivations, and challenges. Australian Journal of Teacher Education, 42(11), 52-64. http://ro.ecu.edu.au/ajte/vol42/iss11/4

Vásquez, V.E.L. (2017). Teachers as researchers: Advantages, disadvantages and challenges for teachers intending to engage in research activities. Retrieved 15 January, 2017 from https://www.academia.edu/719736.

Wadeecharoenrat, T., Methakunavudhi, P., \& Ritcharoon, P. (2012). Development of an empowerment model to enhance research potential of Rajabhat University faculty members. Journal of Education Studies, 40(1), 172-191.

Williams, R., Brien, K., Sprague, C., \& Sullivan, G. (2008). Professional learning communities: developing a school-level readiness instrument. Canadian Journal of Educational Administration and Policy, 74, 1-17. https://files.eric.ed.gov/fulltext/EJ807003.pdf

Wongwanich, S. (2006). Classroom Action Research ( $9^{\text {th }}$ ed.). Bangkok: Chulalongkorn University Press. 